ARTICLE

\title{
Kainate receptor auxiliary subunit NETO2 is required for normal fear expression and extinction
}

Marie Mennesson ${ }^{1,2}$, Emilie Rydgren ${ }^{1}$, Tatiana Lipina ${ }^{3,4,5,6}$, Ewa Sokolowska ${ }^{1}$, Natalia Kulesskaya ${ }^{1}$, Francesca Morello ${ }^{1}$, Evgueni Ivakine ${ }^{7}$, Vootele Voikar $\mathbb{B}^{8}$, Victoria Risbrough $\mathbb{1 D}^{9,10}$, Juha Partanen ${ }^{1}$ and liris Hovatta $\mathbb{D}^{1,2}$

NETO1 and NETO2 are auxiliary subunits of kainate receptors (KARs). They interact with native KAR subunits to modulate multiple aspects of receptor function. Variation in KAR genes has been associated with psychiatric disorders in humans, and in mice, knockouts of the Grik1 gene have increased, while Grik2 and Grik4 knockouts have reduced anxiety-like behavior. To determine whether the NETO proteins regulate anxiety and fear through modulation of KARs, we undertook a comprehensive behavioral analysis of adult $\mathrm{Neto}^{-1-}$ and Neto2 ${ }^{-1-}$ mice. We observed no differences in anxiety-like behavior. However, in cued fear conditioning, Neto $2^{-/}$, but not Neto $1^{-/-}$mice, showed higher fear expression and delayed extinction compared to wild type mice. We established, by in situ hybridization, that Neto2 was expressed in both excitatory and inhibitory neurons throughout the fear circuit including the medial prefrontal cortex, amygdala, and hippocampus. Finally, we demonstrated that the relative amount of synaptosomal KAR GLUK2/3 subunit was $20.8 \%$ lower in the ventral hippocampus and $36.5 \%$ lower in the medial prefrontal cortex in $\mathrm{Neto}^{-/-}$compared to the Neto $2^{+/+}$mice. The GLUK5 subunit abundance was reduced $23.8 \%$ in the ventral hippocampus and $16.9 \%$ in the amygdala. We conclude that Neto 2 regulates fear expression and extinction in mice, and that its absence increases conditionability, a phenotype related to post-traumatic stress disorder and propose that this phenotype is mediated by reduced KAR subunit abundance at synapses of fear-associated brain regions.

Neuropsychopharmacology (2019) 44:1855-1866; https://doi.org/10.1038/s41386-019-0344-5

\section{INTRODUCTION}

NETO1 and NETO2 are CUB-domain containing proteins that interact with native kainate receptor (KAR) subunits. Defined as auxiliary subunits, they modulate functional properties of KARs, including desensitization kinetics and synaptic currents [1-4], and post-synaptic abundance [4-6]. NETO1 and NETO2 interact with cytoplasmic scaffolding proteins through their PDZ-ligand domain to form stable macromolecular complexes with KARs $[1,5]$. In addition to KARs, NETO1 is an auxiliary subunit of N-methyl-Daspartate receptor (NMDAR) [1] while NETO2 interacts with $\mathrm{K}-\mathrm{Cl}$ co-transporter 2 (KCC2) [7].

Although NETO1 and NETO2 are highly homologous, their brain expression patterns differ considerably. NETO2 expression is highest in the cerebellum where it plays a crucial role in determining KAR subunit composition at the post-synaptic density [5]. The expression of NETO1 is highest in the hippocampus (Hpc) [3], where it regulates KAR-mediated excitatory post-synaptic currents $[4,8]$ and axonal targeting of KARs [9]. Recently Wyeth et al. [8] showed that both NETO1 and NETO2 tonically inhibit cholecystokinin (CCK)-expressing interneurons and that NETO1 regulates KAR-mediated excitation of interneurons in the developing Hpc. However, the roles of NETO1 or NETO2 in other brain regions have not been investigated thus far. Consequently, little is known about the contribution of the NETO proteins to complex behaviors. In accordance with the central role of the $\mathrm{Hpc}$ in the regulation of spatial memory, Neto $1^{-1-}$ mice have decreased spatial memory both in the Morris water maze (MWM) and displaced object (DOR) tasks [1], while the behavioral phenotypes of Neto $2^{-1-}$ mice have not been previously investigated.

KARs are members of the ionotropic glutamate receptor (iGluR) family, which mediates fast excitatory neurotransmission in the central nervous system. They are composed of five subunits, designated GLUK1-5 (encoded by Grik1-5 genes), which localize to distinct brain regions, cell types, and subcellular compartments [10-13]. In addition to their post-synaptic actions that are similar to the other iGluR family members, KARs modulate presynaptic neurotransmitter release at both excitatory [14-16] and inhibitory synapses $[17,18]$. Variants in the GRIK2 gene have been associated with obsessive-compulsive disorder [19] and variants in GRIK5 with bipolar disorder [20]. Moreover, significant decreases in the expression levels of GRIK1 and GRIK2 subunits have been reported in entorhinal and perirhinal cortices from bipolar disorder, major depression, and schizophrenia patients [21]. In mice, knockouts of the Grik1 gene have increased anxiety-like behavior [22] while Grik2 and Grik4 knockouts have reduced anxiety-like behavior $[23,24]$.

\footnotetext{
${ }^{1}$ Molecular and Integrative Biosciences Research Program, University of Helsinki, Helsinki, Finland; ${ }^{2}$ Department of Psychology and Logopedics, Medicum, University of Helsinki, Helsinki, Finland; ${ }^{3}$ Lunenfeld Tanenbaum Research Institute at Mount Sinai Hospital, Toronto, ON, Canada; ${ }^{4}$ Federal State Budgetary Scientific Institution, Scientific Research Institute of Physiology and Basic Medicine, Novosibirsk, Russia; ${ }^{5}$ Novosibirsk State University, Novosibirsk, Russia; ${ }^{6}$ Department of Pharmacology and Toxicology, University of

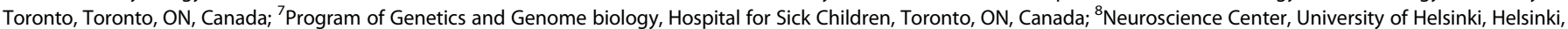
Finland; ${ }^{9}$ Veterans Affairs, La Jolla, CA, USA and ${ }^{10}$ Department of Psychiatry, University of California, San Diego, CA, USA

Correspondence: liris Hovatta (iiris.hovatta@helsinki.fi)
}

Received: 2 October 2018 Revised: 23 January 2019 Accepted: 12 February 2019

Published online: 15 February 2019 
Considering the importance of NETO proteins in the modulation of KAR function, we hypothesized that they may regulate anxiety behavior and undertook a comprehensive behavioral screen of anxiety-like and fear-related behaviors in $\mathrm{Neto}^{+/+}, \mathrm{Neto}^{-1-}$, $\mathrm{Neto}^{+/+}$, and Neto2 $2^{-1-}$ mice. We demonstrated that NETO2 is required for normal fear expression and extinction in cued fear conditioning, phenotypes present in human anxiety disorder patients [25]. Moreover, in fear-related brain regions, we found both that Neto2 was expressed in excitatory and inhibitory neurons, and that the abundance of KAR subunits GLUK2/3 and GLUK5 was reduced at synapses in $\mathrm{Neto}^{-1-}$ mice. Altogether these results establish that NETO2 is required for normal fear expression and extinction in mice, and this phenotype may be mediated by reduced synaptic KAR abundance in the fear circuit.

\section{MATERIALS AND METHODS}

Animals

Neto 1 and Neto2 knockout (KO) mice were generated as described before $[1,4]$ and were $8-12$ weeks old at the time of experiments. The tested wild type (WT) and KO mice were littermates, and the experimenter was blind to their genotype during behavioral testing. Mice were maintained at the Laboratory Animal Centre (LAC) of the University of Helsinki in Finland or at the Toronto Centre of Phenogenomics (TCP) in Canada. Animal procedures were approved by the project authorization board of the Regional State Administration Agency for Southern Finland and carried out in accordance to directive 2010/63/EU of the European Parliament and of the Council and the Finnish Act on the Protection of Animals Used for Science or Educational Purposes (497/2013), and by the Animal Care and Use Committee of the TCP in accordance with the requirements of the Province of Ontario Animals for Research Act 1971 and the Canadian Council on Animal Care. See Supplementary Material and Methods for details.

\section{Behavioral testing}

Elevated plus maze (EPM) test: Mice were placed in the center zone of an elevated $(40 \mathrm{~cm})$ plus-shaped Plexiglass maze composed of two open and two closed arms (length $30 \mathrm{~cm}$, width $5 \mathrm{~cm}$, closed arm wall height $15 \mathrm{~cm}$ ) and video-tracked for $5 \mathrm{~min}$ using EthoVision XT10 software (Noldus, Wageningen, Netherland).

Open field (OF), Forced Swim (FST), and Elevated zero maze (EZM) tests: were carried out as previously [26]. FST was also used as a stressor before measurement of blood corticosterone levels, thus $30 \mathrm{~min}$ after the test mice were anesthetized with $4 \%$ isoflurane and blood samples were collected from the submandibular vein. In the EZM, the risk assessment zone was determined as $5 \mathrm{~cm}$ at the border of closed and open areas.

Light/dark box (LD) test: The same chamber as used for the OF was divided in light and dark compartments $(27 \mathrm{~cm} \times 13 \mathrm{~cm} \times 20$ $\mathrm{cm}$ ) with a hole in between. Mice were placed in the dark compartment and allowed to explore the compartments for $5 \mathrm{~min}$.

Contextual fear conditioning: was performed as previously described [27] using the TSE system. Context A was a transparent chamber $(23 \mathrm{~cm} \times 23 \mathrm{~cm} \times 35 \mathrm{~cm})$ with a grid floor delivering foot shock [unconditioned stimulus (US), $0.6 \mathrm{~mA}, 2 \mathrm{~s}$ ]. During acquisition 3x US were delivered (ITI 60-90s after $180 \mathrm{~s}$ habituation period). Context memory retrieval was assessed by exposure to the same context for $300 \mathrm{~s}$ and freezing was measured with threshold of $2 \mathrm{~s}$.

Cued fear conditioning and extinction: were performed using the same system as contextual fear conditioning. During acquisition in context $\mathrm{A}$, a sound cue [conditioned stimulus (CS), $76 \mathrm{~dB}$, pulsed 5 $\mathrm{Hz}, 30 \mathrm{~s}$ ] was delivered three times [inter-trial-interval (ITI) $30 \mathrm{~s}$ ] followed by a US $(0.6 \mathrm{~mA}, 2 \mathrm{~s})$. Context memory retrieval was assessed the next day by exposure to the context A without CS for $240 \mathrm{~s}$. Two hours later, cue memory retrieval was tested by presenting 2 CSx $60 \mathrm{~s}$ in the same chamber but with black wall and white floor, and a layer of wood chips (bedding material) placed under the removable floor to give a distinctive odor to the context (context B). On the third day, extinction of cued fear conditioning was carried out by presenting $20 \times 30$ s CS (ITI 2 s) in context B. Percent time freezing during extinction was analyzed as an average of $4 \mathrm{CS}$ presentations. Extinction retrieval was measured $24 \mathrm{~h}$ later by presenting $4 \times 30 \mathrm{~s}$ CS (ITI $2 \mathrm{~s}$ ) in context $B$. To assess group differences in the rate of extinction learning we calculated a percentage of extinguished mice using Kaplan-Meier survival analysis to normalize for the higher baseline freezing observed between genotypes. Freezing at the beginning of extinction (CS 1-4) was taken as the 100\% freezing value for each animal. Then percent time freezing during each CS presentation was considered as survival (above $50 \%$ freezing) or no survival (below 50\% freezing).

Morris water maze (MWM) and Spatial and Novel object recognition tasks: were conducted at the TCP with male mice, as previously [1]. See Supplementary Material and Methods.

Spontaneous alternation: task was conducted as previously described [28] using a 7-trial task with $30 \mathrm{~s}$ delay interval (6 alternations) in a gray Plexiglas T-shaped maze. Alternation was graded by giving a value of 1 if an alternation happened between two consecutive trials or a value of 0 if the mouse did not alternate. The sum of these values was considered the total alternation score. Alternation (\%) was calculated by dividing the alternation score by the maximum score value (alternation score / $6 \times 100)$.

Stress-induced hyperthermia $(S / H)$ : was assessed by rectal temperature measurement using a lubricated rectal thermometer probe. Temperatures were taken at $t 1=0 \mathrm{~min}$ and $t 2=10 \mathrm{~min}$ between which mice were returned to the home cage. The first temperature measurement indicated baseline temperature and represented the stressful event. Stress-induced hyperthermia was calculated by $t 2-t 1$.

Saccharin preference (SP): was assessed in home cages. On the first day, animals were habituated to the drinking tubes. During the three following days mice had free access to both water and $0.5 \%$ saccharin bottles, which were inversed every day to avoid side preference bias. Tube weight (g) was measured each testing day to calculate liquid consumption. Saccharin preference score (\%) was calculated by saccharin consumption/total liquid consumption $\times 100$.

Home cage activity, acoustic startle reflex (ASR) and hot plate (HP) test: see Supplementary Material and Methods.

\section{Corticosterone ELISA assay}

Blood samples were left undisturbed for 15-30 min at room temperature to clot, and then centrifuged at 1000-2000 $\mathrm{g}$ for 10 min at $4{ }^{\circ} \mathrm{C}$. Resulting serum was collected immediately and stored at $-80^{\circ} \mathrm{C}$. ELISA assay was performed as instructed in the Corticosterone High Sensitivity EIA kit (Immunodiagnostic Systems, The Boldons, U.K).

In situ hybridization (ISH)

Mice were injected with a lethal dose $(600 \mathrm{mg} / \mathrm{kg})$ of pentobarbital (Mebunat Vet $60 \mathrm{mg} / \mathrm{ml}$, Orion Pharma) and transcardially perfused with phosphate buffer (PBS), followed by $4 \%$ paraformaldehyde (PFA) in PBS, both at $37^{\circ} \mathrm{C}$. Brains were post fixed 2-4 days in PFA at $4{ }^{\circ} \mathrm{C}$, embedded in paraffin blocks and sectioned $(10 \mu \mathrm{m})$ using a Leica RM2255 microtome (Leica Biosystems, Nussloch, Germany). Nonradioactive ISH using probes coupled with either digoxin (DIG) or fluorescein (F) was performed as previously described [29], see Table S1 and Supplementary Material and Methods for details. Brain sections were imaged using Axio Imager 2 (Carl Zeiss, Oberkochen, Germany), processed and exported with Zeiss Zen Lite Software, and background was adjusted with Photoshop software (Abode, Mountain View, CA, USA). Imaging was restricted to specific bregma coordinates: 
mPFC between 1.9 and 1.7, $\mathrm{dHpc}$ and Amg between -1.5 and -2.0 , and $\mathrm{vHpc}$ between -2.9 and -3.3 .

Brain lysates and synaptosomal fraction enrichment Brain regions of interest (see Fig. 6a) were dissected, snap frozen, and stored at $-80^{\circ} \mathrm{C}$. mPFC and Amg were dissected using a micropunch (needle gauge 16). For lysates, tissue was homogenized in RIPA buffer [150 mM NaCl, $1 \%$ Triton X-100, $0.5 \%$ sodium deoxycholate, $0.1 \% \mathrm{SDS}, 50 \mathrm{mM}$ Tris $\mathrm{HCl} \mathrm{pH}=8.0$, and protease cocktail (Sigma-Aldrich, Saint-Louis, MI, USA)] using Precellys 24 homogenizer (Bertinlnstruments, Montigny-le-Bretonneux, France), incubated $1-2 \mathrm{~h}$ under constant agitation at $4{ }^{\circ} \mathrm{C}$ and centrifuged for $20 \mathrm{~min}$ at $12,000 \mathrm{rpm}$. Synaptosomal fraction was obtained as previously described [30]. mPFC and Amg samples were pooled ( $n=2-5$ animals/pool).

Immunoblot analysis

Proteins were size-separated by electrophoresis using 4-20\% acrylamide precast gels and transferred to a nitrocellulose membranes (BioRad, Hercules, CA, USA). Membrane was incubated for $1 \mathrm{~h}$ at room temperature in blocking solution (TBST $+10 \%$ non-fat milk powder or 3-5\% BSA, depending on the primary antibody) prior to overnight incubation with primary antibody at $4{ }^{\circ} \mathrm{C}$ : rabbit anti-NETO2 $(1: 1,000 ; 10 \%$ milk, gift from Dr. Roderick R. Mclnnes), mouse anti-PSD-95 (1:1,000 in TBST+3\% BSA, \#sc-32290, Santa Cruz Biotechnology, Dallas, TX, USA), mouse anti-synaptophysin (1:300, 5\% BSA, \#S5768, Sigma-Aldricht, SaintLouis, MO, USA), rabbit anti-GLUK2/3 (1:1,000, 10\% milk, \#04-921, Millipore, Billerca, MA, USA), rabbit anti-GLUK5 (1:1,000, 10\% milk, \#06-315, Millipore, Billerca, MA, USA), and mouse anti-b-actin (1:2,000, 10\% milk, \#A1978, Sigma-Aldricht, Saint-Louis, MO, USA). They were then washed and incubated with secondary antibody at room temperature: goat anti-rabbit or goat anti-mouse HRP depending on the primary antibody $(1: 5,000$ in primary antibody saturation solution, \#115-035-144 and \#115-035-146, Jackson ImmunoResearch, West Grove, PA, USA). Signal was visualized using Pierce ECL Western Blotting Substrate (ThermoFisher Scientific, Waltham, MA, USA) and membranes were read using SynGen gel doc system G:Box (Syngen, Frederike, MD, USA) or Biospectrum imaging system (Analytik Jena US LLC, Upland, CA, USA). Protein band intensity was quantified using ImageJ version $1.47 \mathrm{v}$ (National Institutes of Health). Band intensity was first normalized with the b-actin signal intensity from the corresponding lane. In Fig. $6 c$ the protein amount of the synaptosomal fraction was then normalized to the homogenate protein amount. The homogenate and synaptosomal fraction samples were always analyzed on the same blot. Ratio of $\mathrm{Neto}^{-/-}$:Neto2 $2^{+/+}$protein abundances in Fig. 6e were calculated as previously $[4,5]$. All samples (KO: $\mathrm{Cb} n=7$, vHpc $n=7, \operatorname{mPFC} n=4$, Amg $n=6$; WT: $\mathrm{Cb}$ $n=7, \operatorname{vHpc} n=7, \operatorname{mPFC} n=5$, Amg $n=6$ ) from the same brain region were ran on the same gel. Each gel run was repeated two times, resulting in three blots per brain region. All blots were analyzed for GLUK2/3, GLUK5, and b-actin signal intensities. GLUK2/3 and GLUK5 signal intensities were then normalized to the b-actin signal intensity. Within each blot, we then calculated the mean normalized signal intensities of all KO and all WT samples, and calculated their ratio (KO/WT). Statistical significance was calculated using one sample $t$-test comparing ratios from the three independent blots of each brain region to a reference value of one (this reference value corresponds to equal protein abundance in KO and WT). For full uncropped blots see Figure S4.

Statistical analysis

Statistical analyses were conducted using SPSS Statistics 24 (IBM, Armonk, NY, USA), GraphPadPrism7 software (GraphPad Software, San Diego, CA, USA), or RStudio (RStudio Inc., Boston, MA, USA). Mean \pm SEM was determined for each group. Data were analyzed using Student's $t$-test, mixed ANOVA, ANCOVA, repeated measure
ANOVA, or Wilcoxon matched-pairs signed rank test, and corrected for multiple comparisons using the BenjaminiHochberg $(\mathrm{BH})$ method [31]. We report adjusted $p$-values $\left(p_{\text {adj }}\right)$ defining significance as $p_{\text {adj }}<0.05$. For more details, see Table S2 and Supplementary Materials and Methods.

\section{RESULTS}

Innate anxiety-like behavior in $\mathrm{Neto}^{-1-}$ and Neto $2^{-1-}$ mice is comparable to $\mathrm{Neto}^{+/+}$and $\mathrm{Neto}^{+/+}$littermate controls

To determine whether either NETO protein has a role in anxietylike behavior, we tested male and female $\mathrm{Neto}^{-1-}$, Neto $1^{+/+}$, $\mathrm{Neto}^{-/-}$, and $\mathrm{Neto}^{+/+}$mice in four paradigms that measure approach-avoidance conflict [elevated plus maze (EPM), elevated zero maze (EZM), light/dark box (LD), and open field (OF) tests]. In the EPM, we found no difference in the time spent in the open or closed arms, or distance traveled in the closed arms between Neto $1^{-1-}$ and $\mathrm{Neto}^{+/+}$or Neto $2^{-/-}$and Neto $2^{+/+}$mice (Fig. $1 \mathrm{a}, \mathrm{b}$, and Figure S1a). However, there was a trend that $\mathrm{Neto}^{-/-}$female mice spent less time $(19.5 \%$, nominal $p=0.012)$ and moved a shorter distance in the closed arms $(23.4 \%$, nominal $p=0.020)$ compared to the $\mathrm{Neto}^{+/+}$mice, although these differences did not survive multiple testing correction. In the EPM, mice have to cross the center zone of the maze to go from one arm to another, and the time spent in the center can confound the analysis. Thus, as we observed these trends, we also tested $\mathrm{Neto}^{-1-}$ and $\mathrm{Neto}^{+/+}$in the EZM, which does not have a center zone. Neto2 ${ }^{-/-}$ mice did not differ from the wild type mice in the time spent in the open areas (Fig. 1c) or in the risk assessment zones (Figure S1b), but Neto $^{-1-}$ females moved again a shorter distance in the closed areas (Figure S1c, $p_{\text {adj }}=0.015$ ). In the LD, we did not observe any differences between $\mathrm{Neto}^{-1-}$ and Neto $1^{+/+}$or Neto $2^{-1-}$ and Neto $2^{+/+}$mice in time spent in the light compartment, latency to enter the light compartment, or the distance traveled in the dark compartment (Fig. 1d, e, and Figure S1d). In the OF, neither $\mathrm{Neto}^{-1-}$ nor $\mathrm{Neto}^{-1-}$ differed from the wild-type mice in the time spent in the center zone (Fig. 1f), but as in the EZM, we observed reduced activity in the periphery of the chamber in female Neto $2^{-1-}$ compared to Neto $2^{+/+}$mice (Figure S1e, $p_{\text {adj }}=0.022$ ).

Since differences in locomotor activity can confound measurement of anxiety-like behavior, we next measured home cage activity of $\mathrm{Neto}^{-1-}, \mathrm{Neto}^{+/+}, \mathrm{Neto} 2^{-/-}$, and Neto $2^{+/+}$mice. No differences were observed between the groups (Figure S1f). Thus, the reduced activity of Neto $2^{-1-}$ mice in the EZM and OF appears to be related to novel environment. To further investigate the basis of the decreased activity in the novel environment of Neto $2^{-/-}$mice, we measured stress-related behavior [stressinduced hyperthermia $(\mathrm{SIH})]$, stress-induced plasma corticosterone (CORT) levels, and depression-like behavior [saccharin preference and forced swim test (FST)] in Neto $2^{-1-}$ and Neto $2^{+/+}$mice. We identified no differences between the genotypes in any of these tests (Fig. 1g-j). Overall, these results demonstrate that Neto2 is not required for normal physiological responses to stress or depressive-like behavior.

Contextual fear conditioning in $\mathrm{Neto}^{-/-}$and $\mathrm{Neto}^{-1-}$ mice We next asked whether Neto1 or Neto2 influence conditioned fearrelated behaviors, and measured contextual fear conditioning using a simple task that creates an association between an unconditioned stimulus (US; electric footstock) and the context (Fig. 2a). During the acquisition phase we measured freezing levels (i.e., fear expression in mice) before (pre-US) and after each US presentation (post-US1, post-US2, and post-US3). We did not observe any statistically significant differences in the freezing levels between $\mathrm{Neto}^{-/-}$and Neto $1^{+/+}$or $\mathrm{Neto}^{-/-}$and Neto2 ${ }^{+/+}$ mice during the acquisition phase (Fig. 2b-e). However, we observed a trend for Neto $2^{-1-}$ male mice for increased response during fear learning (nominal $p=0.013, p_{\text {adj }}=0.055$ ), but this did 

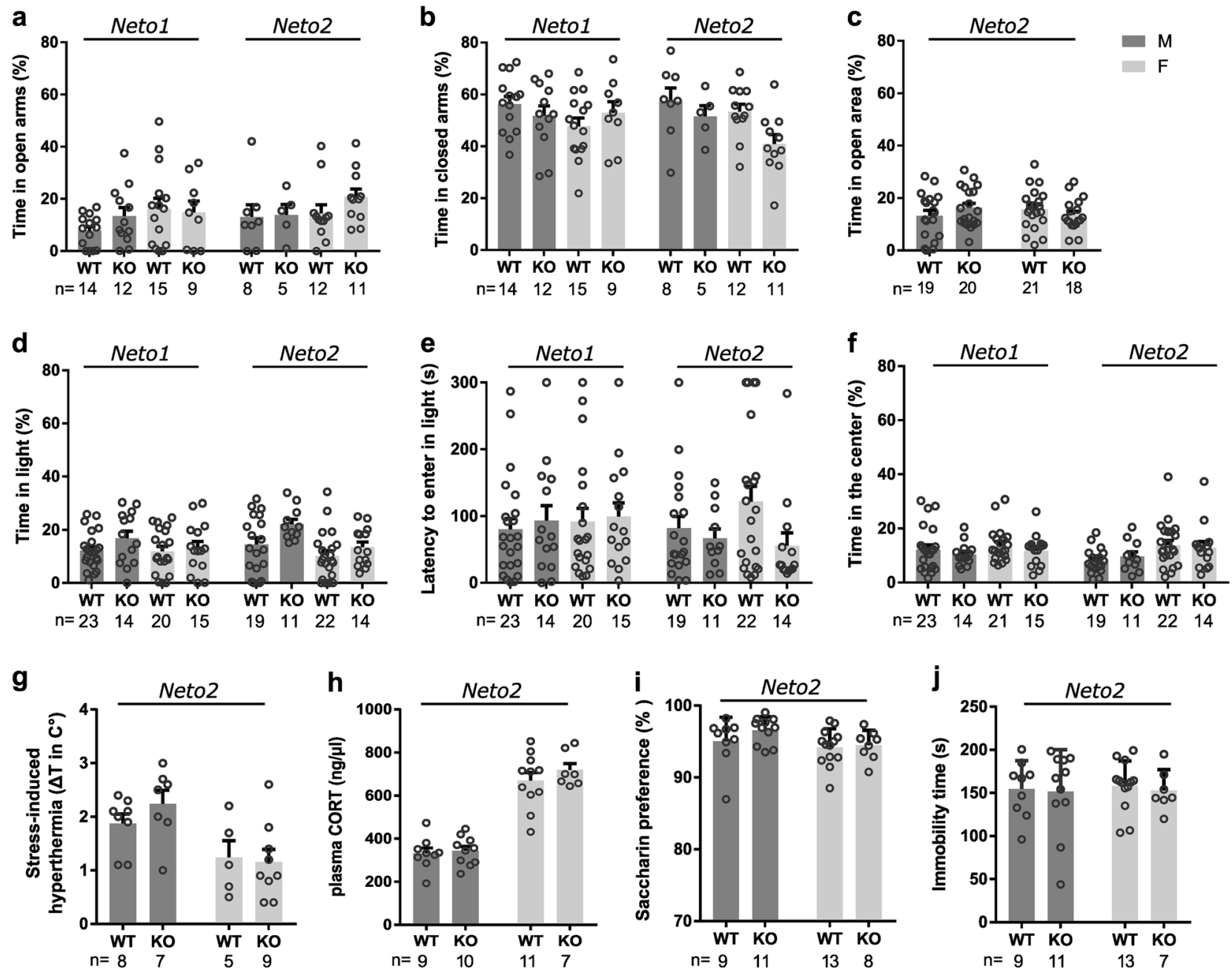

Fig. 1 No difference in anxiety-like behavior between $\mathrm{Neto}^{-/-}$and $\mathrm{Neto}^{+/+}$or Neto $2^{-/-}$and Neto2 ${ }^{+/+}$mice. Results from the elevated plus maze $(\mathbf{a}, \mathbf{b})$, the elevated zero maze $(\mathbf{c})$, the light/dark box test $(\mathbf{d}, \mathbf{e})$, the open field test $(\mathbf{f})$, the stress-induced hyperthermia $(\mathbf{g})$, the stressinduced plasma corticosterone (CORT) levels (h), the saccharin preference (i), and the forced swim test (j). Each dot represents one animal, $\mathbf{M}$ males and $\mathrm{F}$ females. Mean \pm 1 standard error is shown. Genotype effect calculated using $t$-test. KO knockout, WT wild type

not result in increased memory retention (Fig. 2d). The following day, we tested context retrieval by placing the mice back in the same context. Only Neto $1^{-1-}$ females demonstrated higher fear expression compared to controls (Fig. 2c, Cx ret $p_{\text {adj }}=0.032$ ). Altogether, these findings suggest that Neto2 does not influence context retrieval after contextual fear conditioning, but that absence of Neto 1 in female mice leads to enhanced fear memory retrieval after contextual fear conditioning.

Neto2 is required for normal cued fear expression and extinction We next assessed cued fear conditioning in Neto $1^{-1-}$, Neto $1^{+/+}$, Neto2 $2^{-/-}$, and Neto2 ${ }^{+/+}$mice (Fig. 3a). In this task a sound cue (conditioned stimulus, CS) is associated with a footstock (US) and thus becomes a predictor of the US. In the acquisition stage, we found that $\mathrm{Neto}^{-1-}$ mice showed higher freezing levels compared to Neto $2^{+/+}$mice (Fig. 3b, c, males $p_{\text {adj }}=0.009$ and females $p_{\text {adj }}=$ 0.018 ), whereas no differences were observed between $\mathrm{Neto}^{-1-}$ and $\mathrm{Neto}^{+/+}$mice during acquisition (Fig. 3d, e).

On the following day we tested context retrieval in the same context in which mice experienced the CS-US association (context A), and cue retrieval in a new context (context B). Neto $2^{-/-}$mice showed higher freezing levels compared to $\mathrm{Neto}^{+/+}$mice during the context retrieval (Fig. 3b, c, males $p_{\text {adj }}=0.023$ and females $\left.p_{\text {adj }}=0.043\right)$, whereas Neto $1^{-/-}$and Neto $1^{+/+}$did not differ in their freezing levels (Fig. $3 \mathrm{~d}, \mathrm{e}$ ). In the cue retrieval, Neto $2^{-1-}$ mice again froze more than Neto $2^{+++}$mice (Fig. 3b, c, males $p_{\text {adj }}=0.019$ and females $p_{\text {adj }}=0.018$ ), but there were no differences between Neto $1^{-1-}$ and Neto $1^{+/+}$animals (Fig. 3d, e). To determine how much the genotype effect on cue retrieval depended on acquisition of fear, we reran the analysis using the freezing level at the end of the acquisition phase (post-CS3) as a covariate. Genotype effects on cue recall were removed, suggesting that the genotype effects on cue recall day were related to level of fear learning acquired rather than increased recall per se.

We also measured fear extinction by presenting the CS 20 times without the US. We recorded freezing before (pre-CS) and during each CS (CS1-20) and analyzed the results in five blocks of four CS. $\mathrm{Neto}^{-1-}$ and $\mathrm{Neto}^{+/+}$mice displayed no differences in freezing levels during extinction or in extinction efficiency (Fig. 3d, e). In contrast, female $\mathrm{Neto}^{-/-}$mice showed significantly higher freezing levels and male $N e t o 2^{-1-}$ mice showed a trend to increased freezing levels compared to Neto $2^{+/+}$mice (Fig. 3b, c, males $p_{\text {adj }}=0.054$ and females $p_{\text {adj }}=0.023$ ). Male Neto ${ }^{-1-}$ mice failed to extinguish the fear memory during the five blocks of extinction while females were successful to extinguish (Fig. 3b, c, $1^{\text {st }}$ vs $5^{\text {th }}$ block in males Neto $2^{+/+} p_{\text {adj }}=0.021$ and Neto $2^{-/-} p_{\text {adj }}=$ 0.44 , and females Neto ${ }^{+/+} p_{\text {adj }}=0.021$ and Neto ${ }^{-1-} p_{\text {adj }}=$ 0.026). To take into account the overall higher fear expression of 
a Day 1

Acquisition
Context A $\stackrel{24 \mathrm{hrs}}{\longrightarrow} \begin{gathered}\text { Context retrieval } \\ \text { Context A }\end{gathered}$
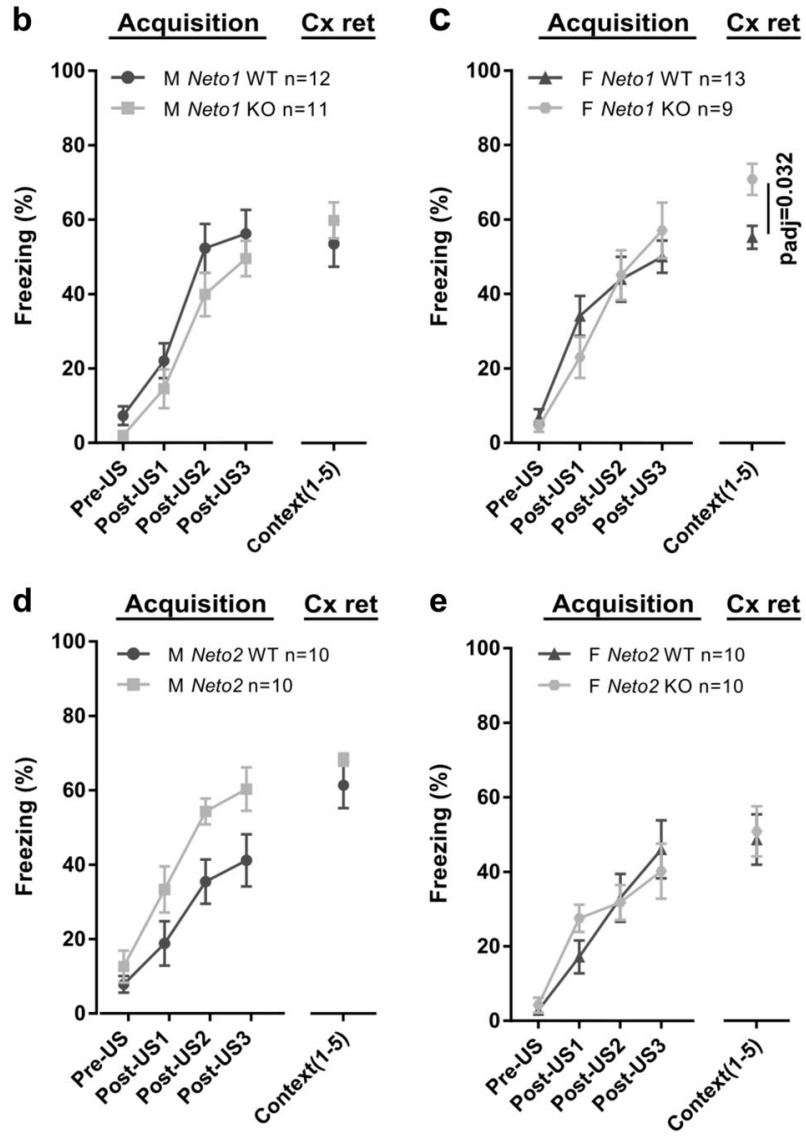

Fig. 2 Contextual fear conditioning in $\mathrm{Neto}^{-/-}, \mathrm{Neto}^{+/+}, \mathrm{Neto}^{-/-}$ and $\mathrm{Neto}^{+/+}$mice. Schematic of the protocol (a). Freezing levels of Neto1 male (b) and female (c), and Neto2 male (d) and female (e) mice during contextual fear acquisition and contextual fear memory retrieval test. Mean \pm 1 standard error is shown. Genotype effect calculated by mixed ANOVA (acquisition) or $t$-test (context test). $P$-values surviving multiple testing correction are shown. $M$ males, F females, KO knockout, WT wild type, US unconditioned stimulus, $\mathrm{Cx}$ ret context retrieval

Neto $2^{-1-}$ mice, we performed a survival analysis (Fig. $3 f-i$ ) that allowed us to normalize for the freezing levels. Briefly, for each mouse we defined extinction as a reduction of freezing to $50 \%$ of the freezing level at the beginning of extinction [CS(1-4)]. In accordance with their similar freezing levels throughout the extinction, $\mathrm{Neto}^{-1-}$ and Neto ${ }^{+/+}$did not show difference in the efficiency of extinction (Fig. 3f, g). However, fear extinction of Neto2 $2^{-1-}$ mice was significantly less efficient compared to the Neto $2^{+/+}$mice (Fig. 3h, i, males $p_{\text {adj }}=0.0017$ and females $p_{\text {adj }}=$ 0.009). Finally, on the following day we tested extinction retrieval. During this test, only female Neto2 ${ }^{-/-}$mice demonstrated higher freezing levels compared to Neto $2^{+/+}$mice (Fig. $3 \mathrm{~b}-\mathrm{e}, p_{\text {adj }}=$ 0.046).

To examine whether the overall increased freezing in $\mathrm{Neto}^{-1-}$ mice could result from higher baseline startle levels, we measured acoustic startle reflex (ASR). Neto2 ${ }^{-1-}$ males showed lower ASR levels compared to the Neto $2^{+/+}$mice (Figure S2a, $p_{\text {adj }}=0.023$ ), suggesting that $\mathrm{Neto}^{-1-}$ mice are not generally more sensitive to startle. To rule out the possibility of higher freezing due to increased pain sensitivity, we performed the hot plate test, but found no differences between the genotypes, showing that Neto $2^{-1-}$ mice are not more sensitive to pain stimuli than their $\mathrm{Neto}^{+/+}$littermates (Figure S2b). Altogether, these results demonstrate less efficient fear extinction in the absence of Neto2, despite the overall higher freezing levels that are not due to higher pain or startle sensitivity.

Brain regions that regulate cued fear conditioning in mice are well established and include mPFC, Hpc, and Amg [32]. Their individual contributions may be distinguished using behavioral tasks that depend on specific brain regions. To characterize the brain regions involved in the $N e t o 2^{-1-}$ fear phenotype we performed the MWM, displaced and novel object recognition (DOR and NOR), and T-maze tasks, which measure Hpc-dependent spatial memory (MWM and DOR) [33, 34], Hpc-, Amg-, and entorhinal cortex-dependent novelty recognition (NOR) [35], and Hpc- and mPFC-dependent spontaneous alternation (T-maze) $[36,37]$. In the MWM, no differences were observed between genotypes in the time spent swimming in any of the quadrants during the probe trial (Fig. $3 \mathrm{j})$, including the SE quadrant $\left(p_{\text {adj }}=\right.$ 0.38) that contained the platform during the training phase. In accordance with this result, Neto $2^{-1-}$ and Neto $2^{+/+}$mice both recognized the displaced objects (DOs) from the non-displaced objects (NDOs) (Fig. 3k, DO vs NDO: Neto ${ }^{+/+} p_{\text {adj }}=0.009$, Neto2 $2^{-/-}$ $\left.p_{\text {adj }}=0.040\right)$. However, in the NOR task Neto $2^{+/+}$mice successfully differentiated between the familiar (FO) and novel object (NO) while Neto2 $2^{-1-}$ failed to do so (Fig. $3 \mathrm{k}$, FO vs DO Neto2 ${ }^{+/+} p_{\text {adj }}=$ 0.009 vs $\mathrm{Neto}^{-1-} p_{\mathrm{adj}}=0.43$ ). Finally, we did not observe working memory deficits in the T-maze as both $\mathrm{Neto}^{-/-}$and Neto $2^{+/+}$mice showed alternation above chance level (Fig. 3l). In conclusion, these experiments establish that in addition to the enhanced cued fear expression and extinction phenotype, Neto $2^{-1-}$ mice have a deficit in recognition of novel objects, a Hpc-, Amg-, and entorhinal cortexdependent behavior. Thus, based on the behavioral phenotype of the Neto2 $2^{-1-}$ mice, which is restricted to specific tasks, we next asked where and in which cell types Neto2 is expressed in the fearrelated brain regions (mPFC, Amg, and $\mathrm{Hpc}$ ).

Neto2 is expressed in both excitatory and inhibitory cells in fearrelated brain regions

To better understand the mechanisms related to the behavioral phenotype of the Neto2 ${ }^{-1-}$ mice, we investigated Neto2 expression pattern that remains poorly characterized. Previous studies have shown that it is highly expressed in the cerebellum [3,5], and that in the $\mathrm{Hpc}$ it co-localizes with major KAR subunits in interneurons [8]. To determine the expression pattern of Neto2 in fear-related brain regions [i.e., mPFC, dorsal and ventral $\mathrm{Hpc}(\mathrm{dHpc}$ and $\mathrm{vHpc}$ ), and Amg, Fig. $4 \mathrm{a}-\mathrm{d}$ ], we carried out in situ hybridization (ISH) on Neto $2^{+/+}$mice and used $\mathrm{Neto}^{-1-}$ mice as controls due to the relatively low level of signal (Fig. 4 and Figure S3). We first established that Neto2 was expressed in each studied brain region (Fig. $4 \mathrm{e}-\mathrm{p}$ ). To identify the specific types of neurons that express Neto2 in these locations, we carried out double ISH using markers for excitatory (vesicular glutamate transporter 1, Vglut1) or inhibitory (glutamate decarboxylase 1, Gad1) neurons (Fig. 5). In the $\mathrm{mPFC}$, Neto2 was expressed in the cingulate (cg1), prelimbic (PL), and infralimbic (IL) cortices (Fig. 4e-g, Figure S3a). In the $\mathrm{dHpc}$ and vHpc, Neto2 was expressed in the CA1, CA3 and dentate gyrus (DG) (Fig. 4h-m, Figure S3b and c). Finally, in the Amg, Neto2 was expressed in both lateral (LA) and basolateral nucleus (BLA) (Fig. 4n, o, Figure S3d). We did not detect any Neto2 expression in the central nucleus (CE, Figure S3d), known to be crucial for fear expression in rodents $[38,39]$. In intercalated cells (ITCs) of the Amg, Neto2 expression was present in few cells (Fig. 4p, Figure S3d). In all four brain regions, Neto2 was expressed in both excitatory and inhibitory cells (Fig. 5). To determine how many Neto2-expressing cells were inhibitory or excitatory neurons, we counted the number of Neto2-positive cells that also express Gad1 or Vglut1 (Fig. 5 d, h, l, p). A larger proportion of Neto2- 

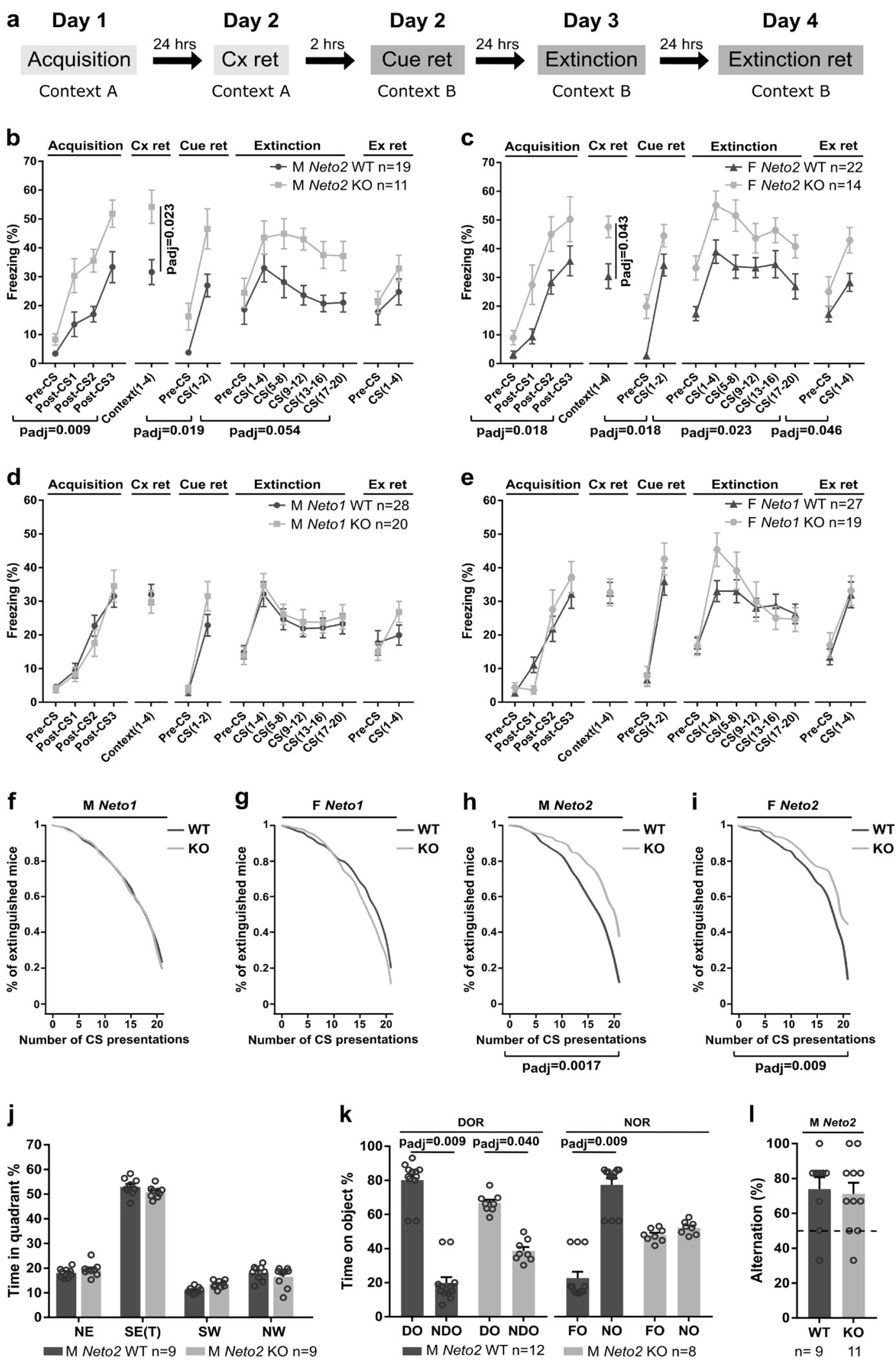

expressing cells in the $\mathrm{Cg} 1, \mathrm{IL}$, and $\mathrm{CA} 1$ were inhibitory than excitatory, while in the DG, vCA1, vCA3, vDG, LA, and BLA the Neto2-expressing cells were mostly excitatory. As expected, Neto2positive cells were Vglut1-negative in the ITCs (Fig. 5p) that are only composed of inhibitory cells. They are involved in fear memory extinction together with IL sub-region of the $\mathrm{mPFC}$ $[40,41]$. Altogether, these results establish that Neto2 is widely expressed in fear-related brain regions, suggesting that other factors than its expression pattern determines the specificity related to its function. 
Fig. 3 Cued fear conditioning and extinction in $\mathrm{Neto}^{-1-}, \mathrm{Neto}^{+/+}, \mathrm{Neto} 2^{-/-}$, and $\mathrm{Neto}^{+/+}$mice, and Morris water maze, displaced and novel object recognition, and spontaneous alternation in Neto $2^{-1-}$ and Neto2 ${ }^{+/+}$mice. Protocol for investigating fear conditioning and extinction memory a. Cx ret context retrieval, Cue ret cue retrieval, Ex ret extinction retrieval. Percent time freezing for Neto2 males (b) and females (c), and Neto 1 males (d) and females (e). Genotype effect calculated by $t$-test (Cx ret) or mixed ANOVA. Percentage of extinguished mice (f, $\mathbf{g}$, $\mathbf{h}$, and i). Genotype effect calculated by log rank (mantel-cox) comparison. $\mathbf{j}$ Time spent in quadrants of the Morris water maze during the probe trial. NE northeast, SE southeast, SW southwest, NW northwest. (T) indicates the quadrant that contained the escape platform during training. Genotype effect calculated by $t$-test. (k) Time spent around objects during displaced and novel object recognition tasks. DO displaced object, NDO non-displaced object, NO novel object and FO familiar object. Genotype effect calculated by Wilcoxon test. (I) Alternation score in the T-maze task. Genotype effect calculated by $t$-test. Each dot represents one animal and dashed line in (I) indicates chance level. Mean \pm 1 standard error is shown. P-values surviving multiple testing correction are shown. M males, F females, KO knockout, WT wild type

a

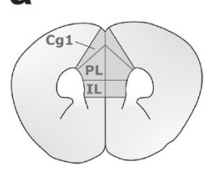

b

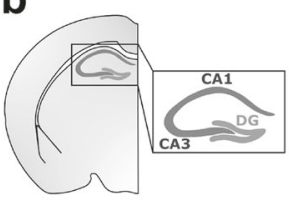

C

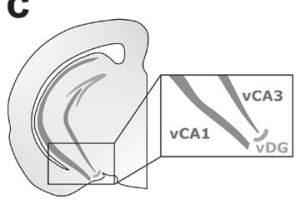

d

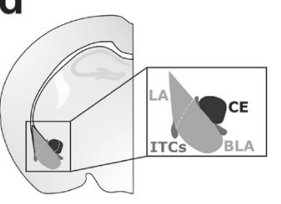

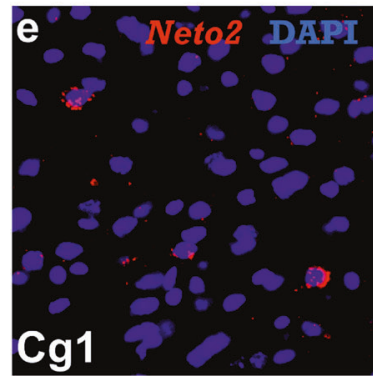
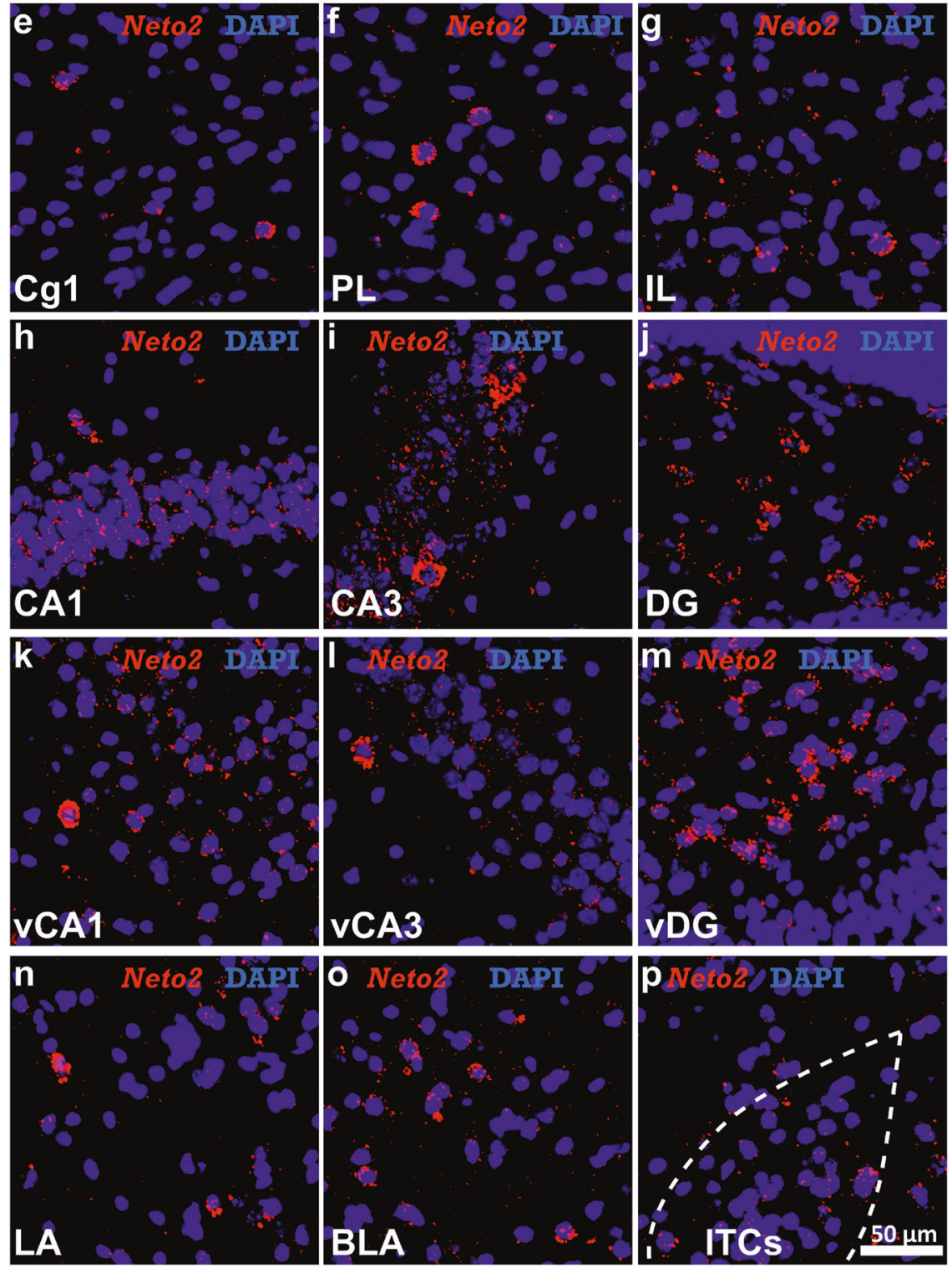

Fig. 4 Neto2 is expressed in the medial prefrontal cortex (mPFC), dorsal, and ventral hippocampus (dHpc and vHpc), and amygdala (Amg). Atlas representation of brain regions analyzed by in situ hybridization: a mPFC (Cg1 cingulate cortex 1, PL prelimbic cortex, and IL infralimbic cortex), b dHpc (CA1, CA3, and DG dentate gyrus), c vHpc (vCA1, vCA3, and vDG), and d Amg (LA lateral amygdala, BLA basolateral amygdala, CE central amygdala, and ITCs intercalated cells) [51]. In situ hybridization (ISH) of Neto2 in e Cg1, $\mathbf{f} P L$, and $\mathbf{g}$ IL subregions of mPFC; $\mathbf{h}$ CA1, i CA3, and $\mathbf{j}$ DG subregions of dHpc; $\mathbf{k}$ vCA1, I vCA3, and $\mathbf{m}$ vDG subregions of vHpc and $\mathbf{n}$ LA, o BLA, and $\mathbf{p}$ ITCs subregions of Amg. Neto2 probe specificity was tested using Neto2 knockout tissue and a sense probe (Figure S3) 

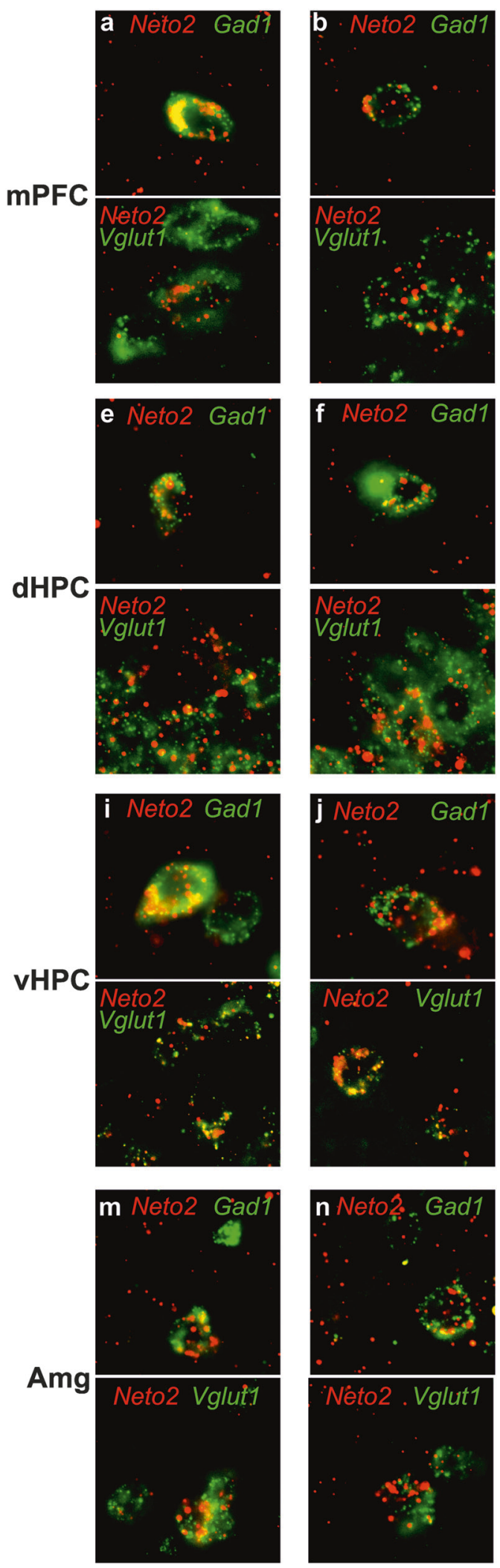

Neto2 ablation reduces KAR subunit abundance at synapses in fear-related brain regions

To assess if the behavioral phenotype of $\mathrm{Neto}^{-1-}$ mice could be due to altered abundance of its binding partners in specific cellular compartment, we investigated KAR subunits in the synapses of
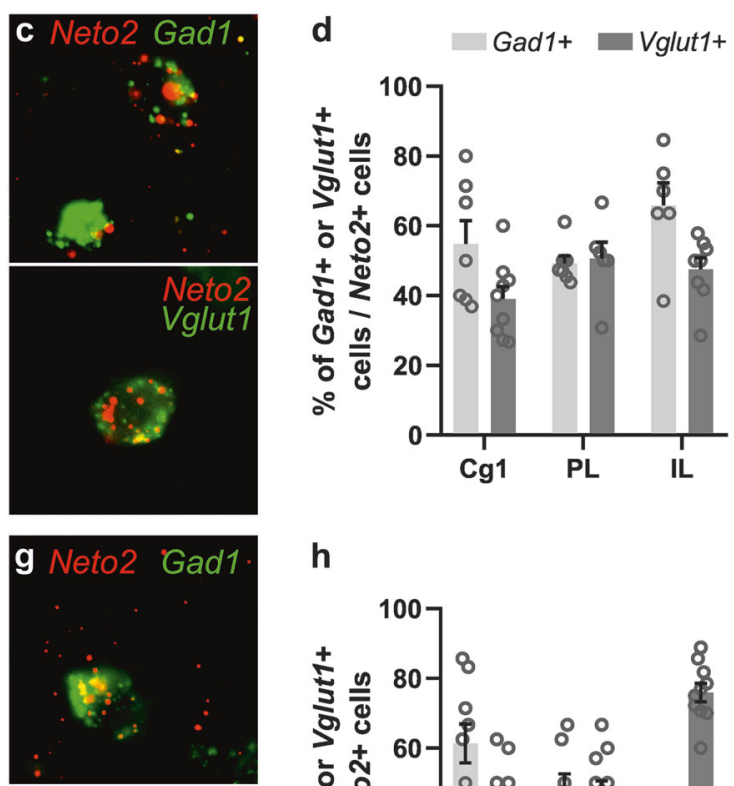

h
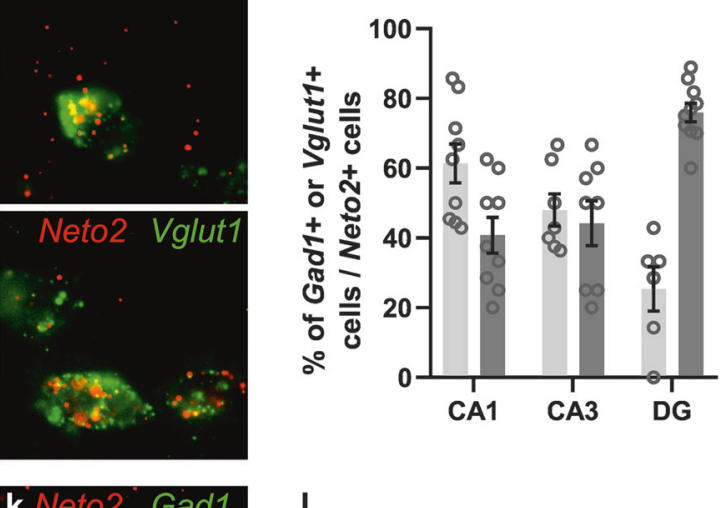

I
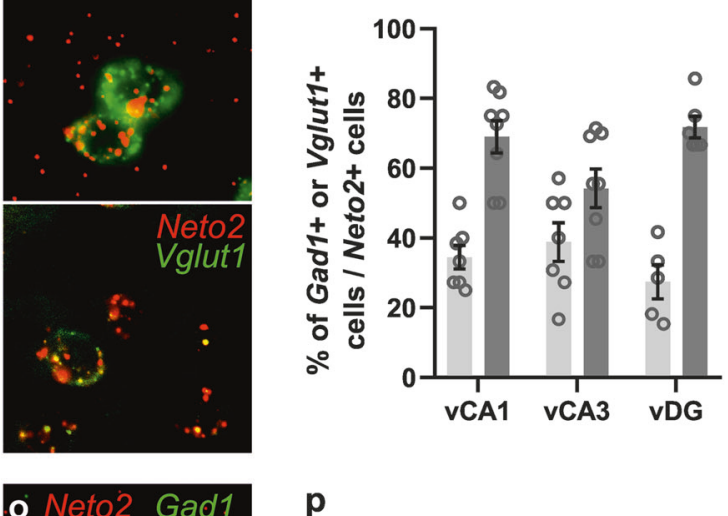

p

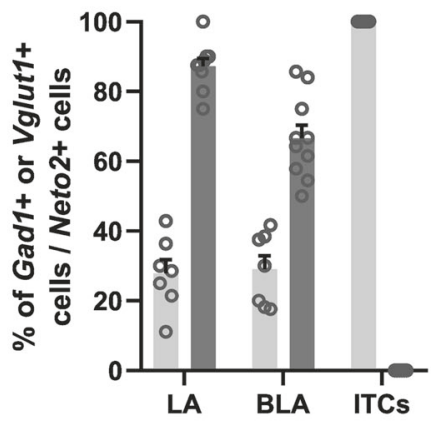


Fig. 5 Neto2 is expressed in both excitatory and inhibitory neurons in fear-related brain regions. High magnification representative images of Neto2 (red) and Gad1 (marker of inhibitory neurons; green) or Vglut1 (marker of excitatory neurons; green) mRNA expression in a Cg1, b PL, and $\mathbf{c}$ IL subregions of mPFC; $\mathbf{d}$ percentage of Neto2-expressing cells that also express Gad1 or Vglut1 in mPFC. Neto2, Gad1, and Vglut1 mRNA expression in e CA1, $\mathbf{f} C A 3$, and $\mathbf{g}$ DG subregions of $\mathbf{d H p c} ; \mathbf{h}$ percentage of Neto2-expressing cells that also express Gad1 or Vglut1 in dHPC. Neto2, Gad1, and Vglut1 mRNA expression in i vCA1, $\mathbf{j}$ vCA3, and $\mathbf{k}$ vDG subregions of vHpc; percentage of Neto2-expressing cells that also express Gad1 or Vglut1 in I vHPC. Neto2, Gad1, and Vglut1 mRNA expression in $\mathbf{m}$ LA, $\mathbf{n}$ BLA, and $\mathbf{o}$ ITC subregions of Amg; percentage of Neto2expressing cells that also express Gad1 or Vglut1 in p Amg. Cg1 cingulate cortex 1, PL prelimbic cortex, IL infralimbic cortex, DG dentate gyrus, LA lateral amygdala, BLA basolateral amygdala, and ITCs intercalated cells

synaptosomal fraction (pre- and post-synaptic regions) from mPFC, $\mathrm{vHpc}$, and Amg using differential ultracentrifugation. Furthermore, we also examined the cerebellum $(\mathrm{Cb})$, where Neto2 is highly expressed, as a technical control for synaptosomal fraction enrichment. We first measured protein abundance of NETO2, GLUK2/3, and GLUK5 in lysates of the four brain regions (Fig. 6a, b). We selected GLUK2/3 and GLUK5 subunits since they are the major KAR subunits in the mouse brain [12] and specific antibodies for them are available. We validated that NETO2 was absent from Neto $2^{-1-}$ tissue, and we did not observe differences between the genotypes in KAR subunit levels (see representative bands in Fig. 6b). Next, we examined the synaptic enrichment by comparing $\mathrm{Cb}$ homogenate $(\mathrm{H})$ and synaptosomal fraction $(\mathrm{SYN})$ protein levels in $\mathrm{Neto}^{+/+}$tissue (Fig. 6c). We demonstrated enrichment in the SYN of both pre- and post-synaptic markers [synaptophysin (SYP) $p=0.012$ and PSD-95 $p=0.002$, respectively] and our proteins of interest (NETO2 $p=1.1 \mathrm{E}^{-6}$, GLUK2/3 $p=0.0006$, and GLUK5 $p=$ $6.5 \mathrm{E}^{-7}$ ), but not the ubiquitous control protein b-actin (Fig. $6 \mathrm{c}$ ). In the vHpc Neto $2^{-1-}$ mice had lower levels of GLUK2/3 $(20.8 \%, p=$ $0.0053)$ and GLUK5 $(23.8 \%, p=0.026)$ in the SYN fraction compared to the $\mathrm{Neto}^{+/+}$mice (Fig. $6 \mathrm{~d}$, e). In the mPFC of Neto $2^{-1-}$ the reduction was even larger for both GLUK2/3 $36.5 \%$, $p=0.038$ ) and GLUK5 (39.5\%), although due to variation between replicates not statistically significant $(p=0.059)$. In the Amg, the difference of GLUK2/3 abundance was not significantly different $(29 \%, p=0.075)$ but the GLUK5 amount was reduced by $16.9 \%$ $(p=0.0014)$ (Fig. $6 \mathrm{~d}, \mathrm{e})$. We did not find differences between Neto $2^{-1-}$ and Neto $2^{+/+}$mice in the $\mathrm{Cb}$ (Fig. $6 \mathrm{~d}$, e). In conclusion, our results establish that Neto 2 is required for normal abundance of major KAR subunits in the synapses of fear-associated brain regions, but not in cerebellum, a region not included in the main fear network.

\section{DISCUSSION}

We have demonstrated that Neto2 is required for expression and extinction of cued fear memories. This finding was specific to Neto 2 and to cued fear conditioning, since Neto $1^{-1-}$ mice did not have this phenotype and Neto $2^{-1-}$ mice did not have deficits in contextual fear conditioning. Furthermore, we established that neither Neto1 nor Neto2 regulate anxiety-like behavior in tests that measure approach-avoidance conflict. However, Neto $2^{-/-}$female mice had reduced activity during these tests, suggesting that NETO2 may influence adaptation to a novel environment in females. We found that the abundance of major synaptic KAR subunits was reduced in fear-related brain regions of $\mathrm{NetO}^{-/-}$vs. Neto $2^{+/+}$mice. Altogether, these results indicate that NETO2 is critical for fear-related behaviors in mice, and that its effect on fear expression and extinction may be mediated by modulation of KAR subunit abundance at synapses in fear-related brain regions.

Although Neto 1 and Neto2 are homologs, their influence on anxiety and fear-related behaviors differed profoundly. The Neto $1^{-1-}$ mice did not differ from the $\mathrm{Neto}^{+/+}$mice in anxietylike behaviors, and they did not have deficits in cued fear conditioning. However, in contextual fear conditioning Neto $1^{-1-}$ females froze more to the context during retrieval compared to the $\mathrm{Neto}^{+/+}$mice, suggesting stronger contextual fear memory in the absence of NETO1. It has been previously shown that Neto $1^{-1-}$ mice have a learning deficit in both MWM and DOR tasks but that they are able to distinguish between familiar and novel objects during the NOR task [1]. Neto1 expression levels are highest in the $\mathrm{Hpc}$ [3], which concurs with the absence of Neto 1 influencing contextual fear conditioning, MWM, and DOR that are all Hpcdependent tasks.

In the $\mathrm{Neto}^{-1-}$ mice, we observed significantly increased fear expression and delayed fear extinction in cued fear conditioning compared to the Neto $2^{+/+}$mice. Neto2 $2^{-/-}$mice showed higher freezing levels in response to the CS even after the first soundshock presentation. We determined that the higher freezing levels of $\mathrm{NetO}^{-/-}$vs. Neto2 $2^{+/+}$mice was not due to higher pain or sensory sensitivity related to the sound cue. The higher fear expression phenotype in Neto2 $2^{-1-}$ mice was specific to cued fear conditioning as we did not observe increased fear expression in these mice during the acquisition or retrieval in the purely contextual fear conditioning. We also observed delayed fear extinction in $\mathrm{Neto} 2^{-/-}$mice compared to the Neto $2^{+/+}$mice even when normalizing for higher freezing levels at recall. Higher fear expression during acquisition of fear memory in mice is reminiscent of higher fear conditionability in humans. Conditionability refers to the situation in which individuals are more prone to acquire conditioned responses to a traumatic unconditioned stimulus. Both higher conditionability and delayed extinction of CS have been observed in post-traumatic stress disorder (PTSD) patients [42-44], indicating that $\mathrm{Neto}^{-1-}$ mice have a PTSD-like phenotype, since they display both of these key PTSD traits.

Anxiety-like behavior, as assessed by the EPM, EZM, LD, and OF that measure approach-avoidance conflict, was normal in the Neto $2^{-1-}$ mice. However, we found that female Neto $2^{-1-}$ mice had reduced activity in novel environments (i.e., EZM and OF) but not in a familiar environment (i.e., home cage) compared to the wildtype mice. Since a novel environment represents a stressful situation, this novelty-induced activity phenotype could result from dysregulation of the stress axis and thus affect other stressrelated behaviors or physiology. However, we did not observe any differences between Neto $2^{-/-}$and $\mathrm{Neto}^{+/+}$mice in other stress or depression-like behaviors, including stress-induced hyperthermia, plasma corticosterone levels, despair-behavior in the FST, or anhedonia as measured by saccharin preference. Even though there were no genotype effects, some of these stress-related phenotypes differed between males and females, although we did not formally test for sex differences due to multiple testing burden. To conclude, Neto2 appears not to be required for innate anxiety, stress-response, or depression-like behavior, but may influence adaptation to novel environments in females.

To further dissect the role of NETO2 in behavioral phenotypes involving the brain regions that regulate fear memory, we further investigated $\mathrm{Neto}^{-1-}$ mice in $\mathrm{MPFC}-, \mathrm{Hpc}-$, and Amg-dependent tasks. The Amg is central for emotional learning, and processes threatening sensory information $[32,45]$. The $\mathrm{Hpc}$ is responsible for contextual encoding of fearful situations [46, 47], and the mPFC regulates fear expression and extinction through projections to the Amg and Hpc $[48,49]$. Neto $2^{-1-}$ mice had no deficits in the Hpc-dependent MWM and DOR spatial tasks [33, 34]. These results are consistent with the lack of context retrieval deficits 
a

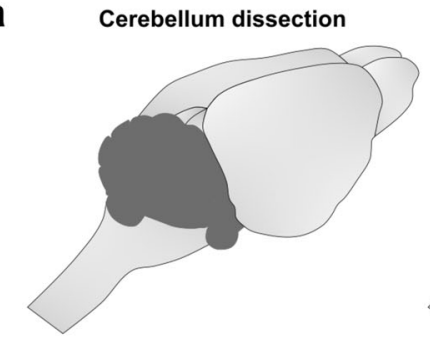

b

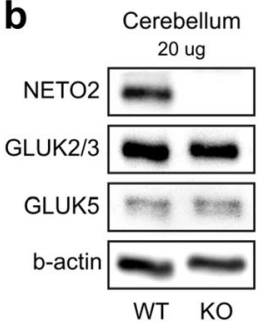

d

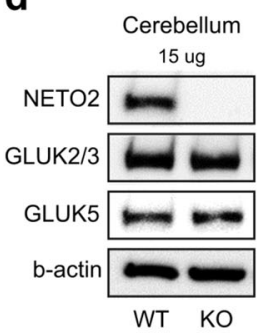

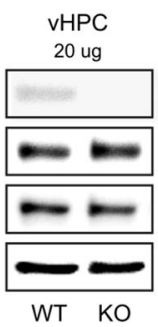

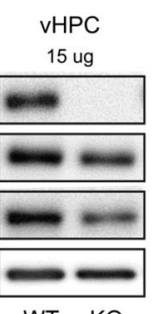

WT KO
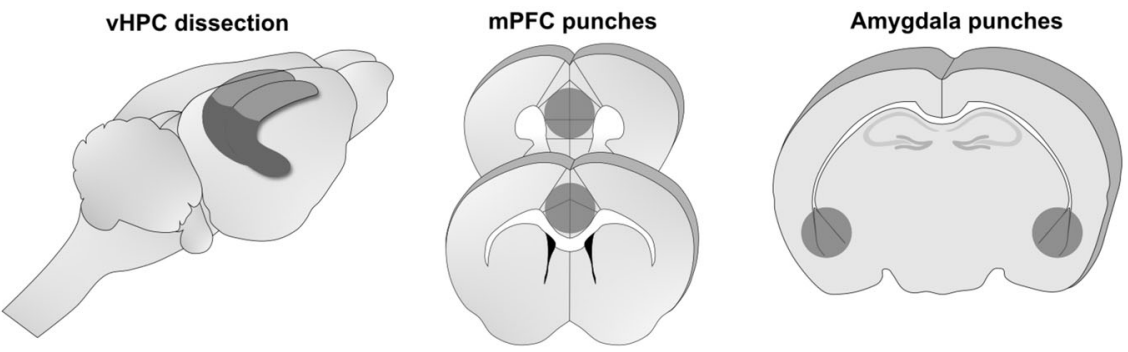

C
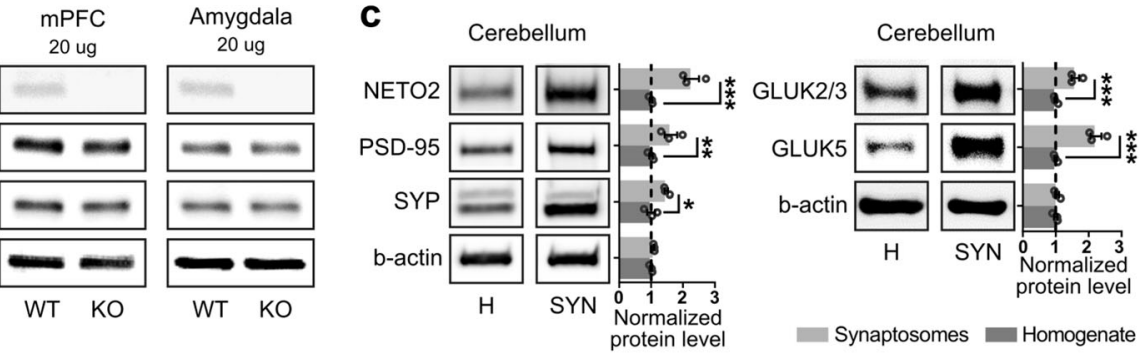

e
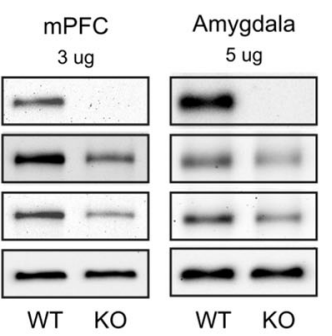

e

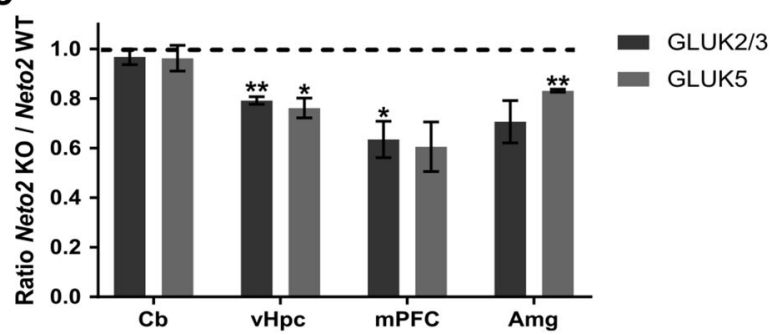

Fig. 6 GLUK2/3 and GLUK5 kainate receptor subunit abundance in lysates and crude synaptosomes from cerebellum (Cb), ventral hippocampus (vHpc), medial prefrontal cortex (mPFC), and amygdala (Amg) of Neto2 $2^{-1-}$ and Neto2 ${ }^{+/+}$mice. a Brain regions dissected for the immunoblot staining. b Representative bands from immunoblots of brain lysates from Neto2 $2^{-1-}$ and $\mathrm{Neto}^{+/+}$mice using antibodies against NETO2, GLUK2/3, and GLUK5. c Validation of synaptosomal enrichment: NETO2 (synaptic marker), synaptophysin (SYP; presynaptic marker), PSD-95 (post-synaptic marker), and KAR subunits GLUK2/3 and GLUK5 from $\mathrm{Cb}$ homogenate $(\mathrm{H}, n=3$ ) and synaptosomes (SYN, $n=3$ ). For quantification, each lane was first normalized to the b-actin signal and then to the homogenate level. $P$-values derived from $t$-test. d Representative bands from synaptosomal immunoblots from $\mathrm{Neto}^{-1-}$ and Neto2 ${ }^{+/+}$mice using antibodies against NETO2, GLUK2/3, and GLUK5. e Ratio of GLUK2/3 and GLUK5 in Neto2 ${ }^{-1-}(\mathrm{Cb}, n=7 ; \mathrm{vHpc}, n=7$; mPFC, $n=4$; Amg, $n=6$ ) vs WT mice (Cb, $n=7$; vHpc, $n=7$; mPFC, $n=5$; Amg, $n=6$ ) calculated from three replicate immunoblots. Prior to calculating the ratio, protein level from each lane was normalized to b-actin loading control. The significance of Neto2 ablation on GLUK2/3 and GLUK5 protein levels measured using $t$-test. ${ }^{*} p<0.05,{ }^{* *} p<0.01$, ${ }^{* * *} p<0.001$. For uncropped blots, see Figure S4

during cued and contextual fear conditioning in $\mathrm{Neto}^{-1-}$ mice. In the NOR task, Neto2 ${ }^{-1-}$ mice failed to distinguish between familiar and novel objects, which suggests a deficit in the Hpc, Amg, and/ or entorhinal cortex functions [35]. Finally, Neto2 ${ }^{-1-}$ mice alternated above chance level in the T-maze, suggesting that Neto2 ablation does not affect Hpc- and mPFC-dependent spontaneous alternation [36,37]. The brain networks involved in spatial memory, novel object recognition, and spontaneous alternation tasks are potentially different from those involved in fear conditioning. Our results demonstrate that NETO2 may contribute to circuits underlying novel object memory, such as $\mathrm{Hpc}$, Amg, and entorhinal cortex.

Although Neto2 is widely expressed throughout the brain, with the highest level in the cerebellum [3,5], little is known about its expression pattern in fear-related brain regions. We established that Neto2 was expressed in both excitatory and inhibitory neurons in fear-related brain regions $\mathrm{mPFC}, \mathrm{dHpc}, \mathrm{vHpc}$, and Amg. This broad expression pattern does not provide additional information to elucidate the mechanisms by which Neto2 regulates fear-related behaviors. Rather, since NETO2 interacts with many scaffolding proteins at both excitatory and inhibitory synapses to form stable macromolecular complexes, it is likely that its specific functions are regulated by such interactions and their subcellular localization [50]. In accordance with this concept, we established that abundances of KAR subunits GLUK2/3 and GLUK5 were 20 to $40 \%$ lower at synapses of fear-related brain regions (vHpc, mPFC, and Amg) but not of $\mathrm{Cb}$ of Neto2 $2^{-1-}$ mice. This reduction was specific to synaptic compartments, since the total protein abundance of GLUK2/3 and GLUK5 were unaffected by Neto2 ablation in all studied brain regions $(\mathrm{Cb}, \mathrm{vHpc}, \mathrm{mPFC}$, and Amg), as previously reported in $\mathrm{HpC}$ and $\mathrm{Cb}[4,5]$. The lower abundance may be due to a default in KAR delivery and/or stability at synapses in the absence of NETO2 $[4,5,8]$. In the $\mathrm{Neto}^{-1-} \mathrm{dHpc}$, major KAR subunit abundance is lower in the PSD, and both KAR- and NMDAR-mediated excitatory post-synaptic currents are reduced [4]. Similarly, the reduced GLUK2/3 and GLUK5 abundance we observed in the synapses of fear-related brain regions in Neto2 ${ }^{-I-}$ mice may cause the reduction of KARmediated synaptic transmission, leading to higher fear expression and delayed extinction.

In conclusion, we have demonstrated that the homologous genes Neto1 and Neto2 have distinct roles in the regulation of behavior. We established that Neto2 is important for fear-related behaviors and that its ablation leads to higher fear expression and extinction deficits, a PTSD-like phenotype. In contrast, Neto1 regulates Hpc-dependent spatial learning memory [1], consistent 
with its high expression levels in the Hpc. Although we did not observe robust differences in anxiety-like behavior, the absence of Neto2 influenced adaptation to novel environment in females, the startle reflex in males, and novel object recognition, which we only measured in males. In keeping with its modulation of KAR function, Neto2 is required to maintain the normal abundance of major KAR subunits at synapses in fear-related brain regions, which may mediate the ability to emotionally process threat cues. Altogether, these findings provide new insight into the role of KAR auxiliary subunit NETO2 in complex behaviors such as fear expression and memory. Our observations suggest the possibility that both KAR and NETO2 function may be compromised in human disorders associated with fear expression and extinction impairment. Identification of the underlying mechanisms of these phenotypes may lead to better understanding of the biological drivers behind anxiety- and fear-related disorders, a requirement for the development of targeted therapies.

\section{FUNDING AND DISCLOSURE}

This work was supported by the Jane and Aatos Erkko Foundation (to I.H.), Sigrid Jusélius Foundation (to I.H.), University of Helsinki (to I.H.), Oskar Öflund Foundation (to M.M.), and the Finnish Cultural Foundation (to M.M.). None of the authors report financial disclosures related to this work.

\section{ACKNOWLEDGEMENTS}

We thank Roderick R. McInnes for Neto1 and Neto2 knockout mice and antibody for NETO2, Saija-Anita Callan for help in behavioral testing, Marijiana Kanisek for performing of MWM test, and Sari Lauri, Ester Orav, Sebnem Kesaf, Anna Kirjavainen, Laura Tikker, and Hovatta lab members for helpful discussions. We thank the Mouse Behavioral Phenotype Facility (MBPF) supported by Biocenter Finland and Helsinki Institute of Life Science, and the Biocomplex Unit (Instruct Center for Virus and Macromolecular Complex Production, ICVIR 2009-2017) for the use of their facilities, and Sari Korhonen from ICVIR for technical help.

\section{ADDITIONAL INFORMATION}

Supplementary Information accompanies this paper at (https://doi.org/10.1038/ s41386-019-0344-5)

Publisher's note: Springer Nature remains neutral with regard to jurisdictional claims in published maps and institutional affiliations.

\section{REFERENCES}

1. Ng D, Pitcher GM, Szilard RK, Sertie A, Kanisek M, Clapcote SJ, et al. Neto1 is a novel CUB-domain NMDA receptor-interacting protein required for synaptic plasticity and learning. PLoS Biol. 2009;7:e41.

2. Zhang W, St-Gelais F, Grabner CP, Trinidad JC, Sumioka A, Morimoto-Tomita M, et al. A transmembrane accessory subunit that modulates kainate-type glutamate receptors. Neuron. 2009;61:385-96.

3. Straub C, Hunt DL, Yamasaki M, Kim KS, Watanabe M, Castillo PE, et al. Distinct functions of kainate receptors in the brain are determined by the auxiliary subunit Neto1. Nat Neurosci. 2011;14:866-73.

4. Tang M, Pelkey KA, Ng D, Ivakine E, McBain CJ, Salter MW, et al. Neto1 is an auxiliary subunit of native synaptic kainate receptors. J Neurosci. 2011;31: 10009-18.

5. Tang M, Ivakine E, Mahadevan V, Salter MW, McInnes RR. Neto2 interacts with the scaffolding protein GRIP and regulates synaptic abundance of kainate receptors. PLoS ONE. 2012;7:e51433.

6. Wyeth MS, Pelkey KA, Petralia RS, Salter MW, McInnes RR, McBain CJ. Neto auxiliary protein interactions regulate kainate and NMDA receptor subunit localization at mossy fiber-CA3 pyramidal cell synapses. J Neurosci. 2014;34:622-8.

7. Ivakine EA, Acton BA, Mahadevan V, Ormond J, Tang M, Pressey JC, et al. Neto2 is a $\mathrm{KCC} 2$ interacting protein required for neuronal $\mathrm{Cl}$ - regulation in hippocampal neurons. Proc Natl Acad Sci USA. 2013;110:3561-6.

8. Wyeth MS, Pelkey KA, Yuan X, Vargish G, Johnston AD, Hunt S, et al. Neto auxiliary subunits regulate interneuron somatodendritic and presynaptic kainate receptors to control network inhibition. Cell Rep. 2017;20:2156-68.
9. Orav E, Atanasova T, Shintyapina A, Kesaf S, Kokko M, Partanen J, et al. NETO1 Guides Development of Glutamatergic Connectivity in the Hippocampus by Regulating Axonal Kainate Receptors. eNeuro. 2017;4:ENEURO.0048-17.2017.

10. Wisden W, Seeburg PH. A complex mosaic of high-affinity kainate receptors in rat brain. J Neurosci. 1993;13:3582-98.

11. Paternain AV, Herrera MT, Nieto MA, Lerma J. GluR5 and GluR6 kainate receptor subunits coexist in hippocampal neurons and coassemble to form functional receptors. J Neurosci. 2000;20:196-205.

12. Watanabe-lida I, Konno K, Akashi K, Abe M, Natsume R, Watanabe M, et al. Determination of kainate receptor subunit ratios in mouse brain using novel chimeric protein standards. J Neurochem. 2016;136:295-305.

13. Wondolowski J, Frerking M. Subunit-dependent postsynaptic expression of kainate receptors on hippocampal interneurons in area CA1. J Neurosci. 2009;29:563-74.

14. Lauri SE, Bortolotto ZA, Bleakman D, Ornstein PL, Lodge D, Isaac JT, et al. A critical role of a facilitatory presynaptic kainate receptor in mossy fiber LTP. Neuron. 2001;32:697-709.

15. Pinheiro PS, Perrais D, Coussen F, Barhanin J, Bettler B, Mann JR, et al. GluR7 is an essential subunit of presynaptic kainate autoreceptors at hippocampal mossy fiber synapses. Proc Natl Acad Sci USA. 2007;104:12181-6.

16. Lauri SE, Segerstrale M, Vesikansa A, Maingret F, Mulle $C$, Collingridge GL, et al. Endogenous activation of kainate receptors regulates glutamate release and network activity in the developing hippocampus. J Neurosci. 2005;25:4473-84.

17. Delaney AJ, Jahr CE. Kainate receptors differentially regulate release at two parallel fiber synapses. Neuron. 2002;36:475-82.

18. Kidd FL, Coumis U, Collingridge GL, Crabtree JW, Isaac JT. A presynaptic kainate receptor is involved in regulating the dynamic properties of thalamocortical synapses during development. Neuron. 2002;34:635-46.

19. Gratacos M, Costas J, de Cid R, Bayes M, Gonzalez JR, Baca-Garcia E, et al. Identification of new putative susceptibility genes for several psychiatric disorders by association analysis of regulatory and non-synonymous SNPs of 306 genes involved in neurotransmission and neurodevelopment. Am J Med Genet B Neuropsychiatr Genet. 2009;150B:808-16.

20. Mattheisen M, Samuels JF, Wang Y, Greenberg BD, Fyer AJ, McCracken JT, et al. Genome-wide association study in obsessive-compulsive disorder: results from the OCGAS. Mol Psychiatry. 2015;20:337-44.

21. Beneyto $M$, Kristiansen LV, Oni-Orisan A, McCullumsmith RE, Meador-Woodruff $\mathrm{JH}$. Abnormal glutamate receptor expression in the medial temporal lobe in schizophrenia and mood disorders. Neuropsychopharmacology. 2007;32: 1888-902.

22. Wu LJ, Ko SW, Toyoda H, Zhao MG, Xu H, Vadakkan KI, et al. Increased anxiety-like behavior and enhanced synaptic efficacy in the amygdala of GluR5 knockout mice. PLoS ONE. 2007;2:e167.

23. Shaltiel G, Maeng S, Malkesman O, Pearson B, Schloesser RJ, Tragon T, et al Evidence for the involvement of the kainate receptor subunit GluR6 (GRIK2) in mediating behavioral displays related to behavioral symptoms of mania. Mol Psychiatry. 2008;13:858-72.

24. Catches JS, Xu J, Contractor A. Genetic ablation of the GluK4 kainate receptor subunit causes anxiolytic and antidepressant-like behavior in mice. Behav Brain Res. 2012;228:406-14.

25. Holmes A, Singewald N. Individual differences in recovery from traumatic fear Trends Neurosci. 2013;36:23-31.

26. Laine MA, Trontti K, Misiewicz Z, Sokolowska E, Kulesskaya N, Heikkinen A, et al Genetic Control of Myelin Plasticity after Chronic Psychosocial Stress. eNeuro. 2018;5:ENEURO.0166-18.2018.

27. Fitzgerald PJ, Pinard CR, Camp MC, Feyder M, Sah A, Bergstrom HC, et al. Durable fear memories require PSD-95. Mol Psychiatry. 2015;20:901-12.

28. Dominguez G, Dagnas $M$, Decorte $L$, Vandesquille $M$, Belzung $C$, Beracochea $D$, et al. Rescuing prefrontal CAMP-CREB pathway reverses working memory deficits during withdrawal from prolonged alcohol exposure. Brain Struct Funct. 2016;221:865-77.

29. Lahti L, Haugas M, Tikker L, Airavaara M, Voutilainen $M H$, Anttila J, et al. Differentiation and molecular heterogeneity of inhibitory and excitatory neurons associated with midbrain dopaminergic nuclei. Development. 2016;143:516-29.

30. Maccarrone G, Filiou MD. Protein profiling and phosphoprotein analysis by isoelectric focusing. Methods Mol Biol. 2015;1295:293-303.

31. Benjamini $Y$, Hochberg Y. Controlling the false discovery rate: a practical and powerful approach to multiple testing. J R Stat Soc Ser B Stat Methodol. 1995;57:11.

32. Tovote P, Fadok JP, Luthi A. Neuronal circuits for fear and anxiety. Nat Rev Neurosci. 2015;16:317-31.

33. Vorhees CV, Williams MT. Assessing spatial learning and memory in rodents. ILAR J. 2014;55:310-32.

34. Vogel-Ciernia A, Wood MA. Examining object location and object recognition memory in mice. Curr Protoc Neurosci. 2014;69:8 31 1-17. 
35. Moses SN, Sutherland RJ, McDonald RJ. Differential involvement of amygdala and hippocampus in responding to novel objects and contexts. Brain Res Bull. 2002;58:517-27.

36. Kirkby RJ, Stein DG, Kimble RJ, Kimble DP. Effects of hippocampal lesions and duration of sensory input on spontaneous alternation. J Comp Physiol Psychol. 1967;64:342-5.

37. Divac I, Wikmark R, Gade A. Spontaneous alternation in rats with lesions in the frontal lobe: an extension of the frontal lobe syndrome. Physiol Psychol. 1975;3:7.

38. LeDoux JE, Iwata J, Cicchetti P, Reis DJ. Different projections of the central amygdaloid nucleus mediate autonomic and behavioral correlates of conditioned fear. J Neurosci. 1988;8:2517-29.

39. Ciocchi S, Herry C, Grenier F, Wolff SB, Letzkus JJ, Vlachos I, et al. Encoding of conditioned fear in central amygdala inhibitory circuits. Nature. 2010;468:277-82.

40. Likhtik E, Popa D, Apergis-Schoute J, Fidacaro GA, Pare D. Amygdala intercalated neurons are required for expression of fear extinction. Nature. 2008;454:642-5.

41. Amano T, Unal CT, Pare D. Synaptic correlates of fear extinction in the amygdala. Nat Neurosci. 2010;13:489-94.

42. Blechert J, Michael T, Vriends N, Margraf J, Wilhelm FH. Fear conditioning in posttraumatic stress disorder: evidence for delayed extinction of autonomic, experiential, and behavioural responses. Behav Res Ther. 2007;45:2019-33.
43. Orr SP, Metzger L, Lasko NB, Macklin ML, Peri T, Pitman RK. De novo conditioning in trauma-exposed individuals with and without posttraumatic stress disorder. J Abnorm Psychol. 2000;109:290-8.

44. Wegerer M, Blechert J, Kerschbaum $\mathrm{H}$, Wilhelm FH. Relationship between fear conditionability and aversive memories: evidence from a novel conditionedintrusion paradigm. PLoS ONE. 2013;8:e79025.

45. Herry $C$, Johansen JP. Encoding of fear learning and memory in distributed neuronal circuits. Nat Neurosci. 2014;17:1644-54.

46. Fanselow MS, Dong HW. Are the dorsal and ventral hippocampus functionally distinct structures? Neuron. 2010;65:7-19.

47. Phillips RG, LeDoux JE. Differential contribution of amygdala and hippocampus to cued and contextual fear conditioning. Behav Neurosci. 1992;106:274-85.

48. Corcoran KA, Quirk GJ. Activity in prelimbic cortex is necessary for the expression of learned, but not innate, fears. J Neurosci. 2007;27:840-4.

49. Marek R, Xu L, Sullivan RKP, Sah P. Excitatory connections between the prelimbic and infralimbic medial prefrontal cortex show a role for the prelimbic cortex in fear extinction. Nat Neurosci. 2018;21:654-8.

50. Jaskolski F, Coussen F, Mulle C. Subcellular localization and trafficking of kainate receptors. Trends Pharmacol Sci. 2005;26:20-6.

51. Franklin K, Paxinos G. The mouse brain in stereotaxic coordinates. Ed 3. New York, NY: Academic Press; 2008. 